Murmurations:

Journal of

Transformative

Systemic

Practice

\title{
Being Systemic as a Way of Life. Reflections on a Trip to China
}

\author{
Chiara Santin
}

\section{Volume 2}

\section{Issue 1}

\section{Spring 2019}

\section{Keywords:}

systemic values, tourist in China, The

Social Graces, diffractive storytelling

\section{Citation Link}

Imagine being a tourist in a foreign land whilst reading this. It can be a magical experience when we are open to being influenced, to engage on a journey which will lead to unexplored and exciting new places, geographically, emotionally and intellectually!

This writing is a patchwork of contributions which invites you to respond and make your own connections and reflections. Perhaps it will inspire you to have new thoughts and exciting ideas of your own which may influence your identity, your therapeutic practices and your unique ways of looking at the world.

Making a patchwork is a laborious and constantly evolving process. It can be stressful, tiring and frustrating too. You are likely to get stuck. You do not know what the end result will be. We have to engage our imagination and enjoy the process of creating moment by moment.

This writing can also be seen as a "diffraction exploration". What does it mean? Karen Barad, (2007) a contemporary feminist philosopher, inspired me to consider reflections as diffractions. In quantum physics, atoms behave in a way that can surprise scientists e.g. the noise of an atom being moved, an additional object in the field of observation, can create a new image, a new way of seeing the materiality of an atom. We tend to think of reflections as a faithful mirror which replicates the object/subject of observation; however, the idea of diffraction challenges us to consider that nothing of what we see and think is a true representation; it's just one specific way of looking at things whilst missing noticing other things.

\footnotetext{
The phenomenon of diffraction does not merely signify the disruption of representationalism and its metaphors of reflection in the endless play of images and its anxieties about copy an original and displacements of the Same elsewhere. (Barad 2007, p.381)
}

During my visit to China I was keen to be just a tourist, relaxing, and exploring. When I realised that I was seeing the Chinese through systemic lenses, I felt inspired to start sharing my reflections on meeting Chinese culture, people and my exploring of an unfamiliar world. Then as a teacher 
I wanted to share my reflections with students on a certificate in systemic practice in London as a way to convey that our living systemic practices become embedded in our identities and how systemic ideas can become alive in other contexts (even on holiday!) and relationships and may take different meanings.

When I shared my experience with students, Freda McEwen responded to my invitation to share their reflections and feedback. I was astonished by her poem and her ability to "live inside me" or "seeing through my eyes" as if she was there with me in China. What a skill to have in relationships and systemic practice! As Barad says, "We are of the universe - there is no inside, no outside. There is only intra-acting from within and as part of the world in its becoming" (Karen Barad 2007, p.396).

My writing was evolving from just one piece of fabric, towards a patchwork of diffractions, i.e. new original pieces connected to the original but beautifully unique to make a whole quilt look complex, rich and interesting. I therefore thought that I should invite a Chinese therapist to respond to my writing with their reflections/diffractions. This was an invitation made to several people and forums. I was frustrated by the lack of response and when Charlotte Chiu responded immediately to my invitation I was grateful and excited. She was open and ready to engage with a stranger (we did not know each other) into a meaning making process of multiple and unique diffractions.

The crucial point is not mirroring but its creative undoing, not sameness reproduced without end but attentiveness to differences that matter (Barad 2007, p.382).

\section{Being an explorer, an invitation to explore with fresh eyes}

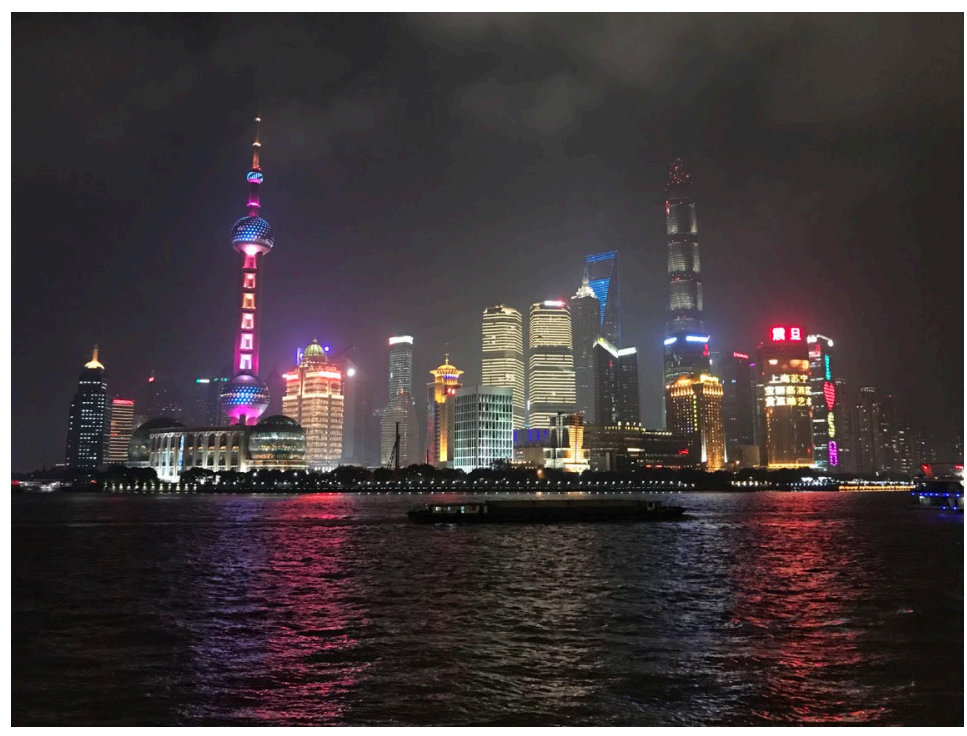

I have been to China a few times thanks to my partner's connections in the field of biomedical sciences. In the last trip more than ever I have been reflecting how much systemic thinking influences my way of being and seeing the world wherever I go. It made me also think about the relevance of some systemic ideas when I meet families in therapy.

Most of the trip was organised by local scientists who looked after us in providing food, accommodation and taking us sightseeing. On a busy day for the rest of the group, I wanted to explore the Chinese world using my natural curiosity about new places and people. I do not speak any Chinese. I tried to convey to the receptionist of the hotel that I was interested in their culture and ordinary living places and asked her what I could visit locally. Her response was exquisite kindness and care which compensated for her little English. She gave me a map and wrote in Chinese on a piece of paper three addresses, one for a natural park, one of a shopping mall and the hotel. I had a map of a 10 million people city but it could not prepare me to 
what I was seeing! The map was just a lifeless illustration of the place as it looked from a navigation point of view. The map looked scary but it was a useful tool to manage my anxiety of getting lost and roughly know where "home" (hotel) was. I soon realised that the map was very different from the Chinese living places and ordinary lives in front of my eyes i.e. large roads, thousands of cars, mopeds, huge skyscrapers under construction, the hazy horizons, the local food kiosks, washing hung in the streets, armies of cleaners collecting rubbish
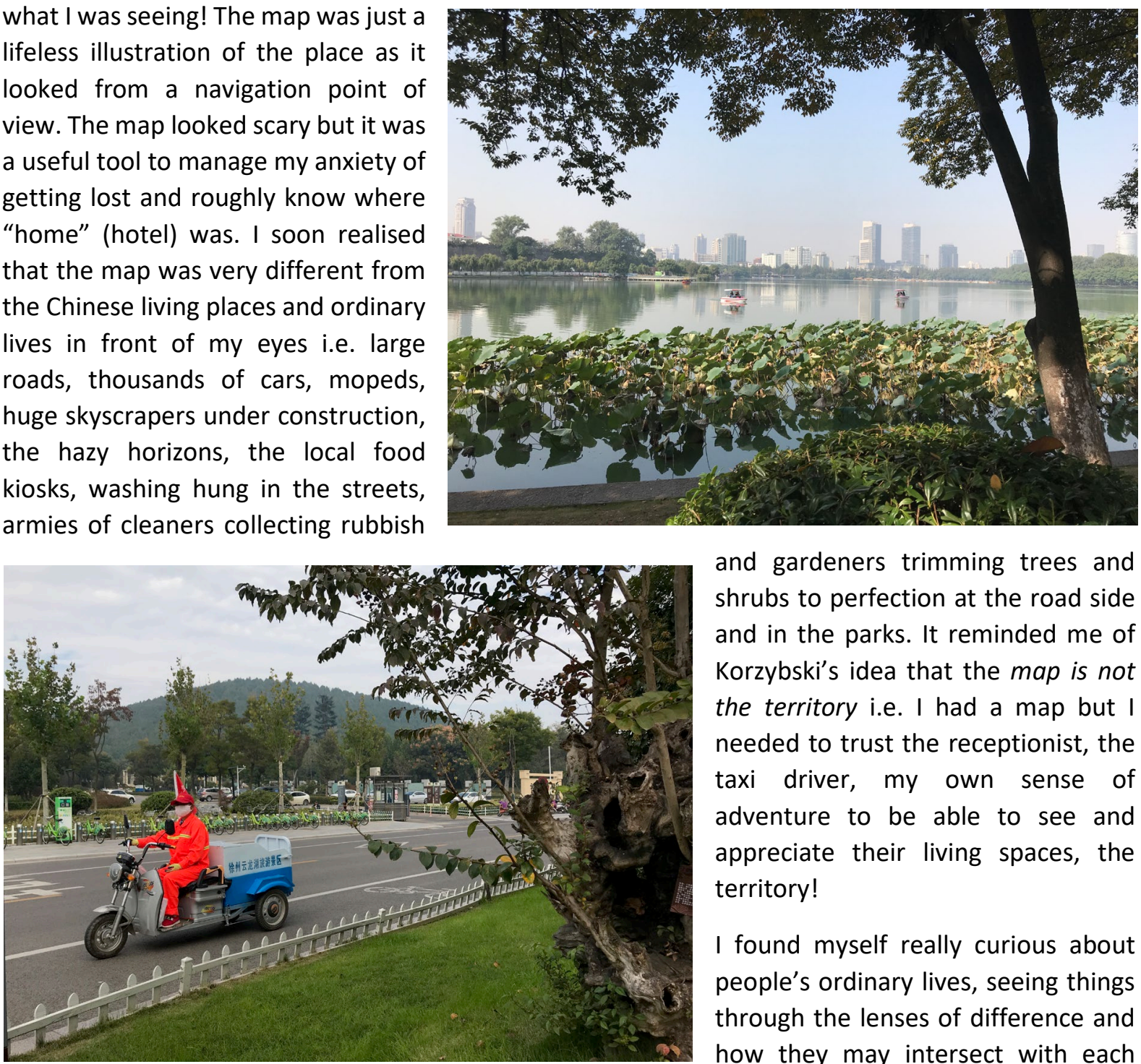

and gardeners trimming trees and shrubs to perfection at the road side and in the parks. It reminded me of Korzybski's idea that the map is not the territory i.e. I had a map but I needed to trust the receptionist, the taxi driver, my own sense of adventure to be able to see and appreciate their living spaces, the territory!

I found myself really curious about people's ordinary lives, seeing things through the lenses of difference and how they may intersect with each

other in unique ways. It made me think about the Social Graces, how some differences became more visible and others remained invisible to my eyes and unvoiced. The intersectionality and combination of multiple aspects of difference were presenting to me as a complex interplay of gender, religion, education, class, disability, age, culture, race and ethnicity, socioeconomics and politics, a complex puzzle which was quite difficult to grasp. I wondered how the Social Graces would translate into Chinese

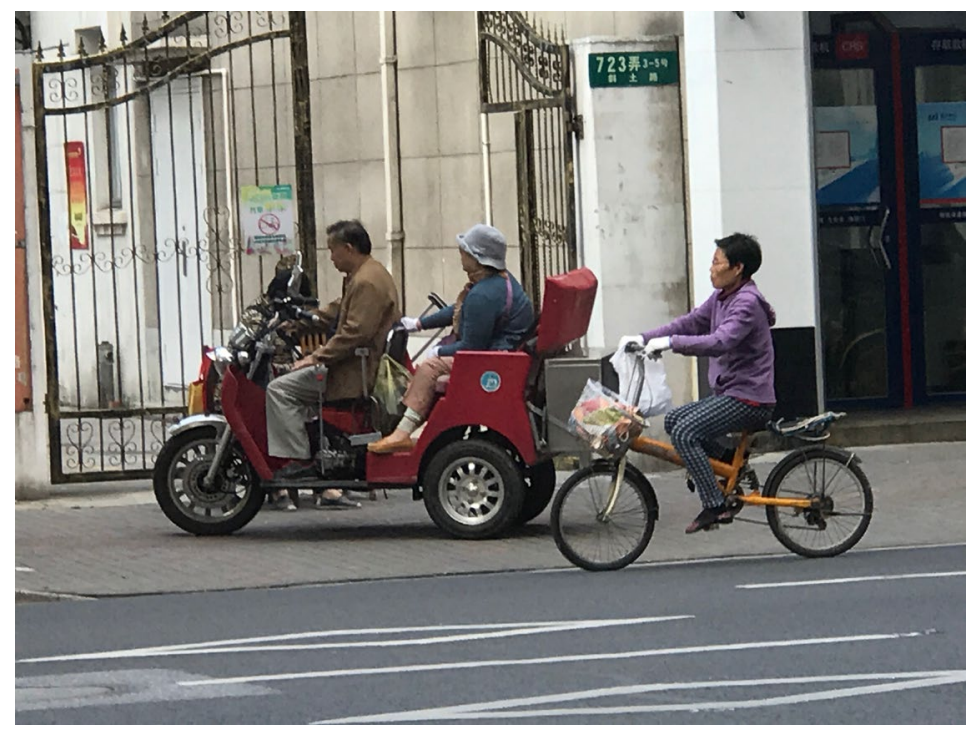
language, maybe a beautiful writing/drawing of letters which could incapsulate the richness as well as the stark contrast in social differences, far from the simplicity of English language. At the same time, I thought about the possible meaning of translating Social Graces in to Italian i.e. le grazie sociali. 
"Grazie" means thank you and/or blessings so I wondered how come that the current landscape of economic-socio-political-cultural-power differences brought and magnified by immigration in Italy are actively rejected rather than being gratefully received. It made me realised how some systemic ideas may make sense in a particular context (The Social Graces were born in a UK training context) and might be difficult to translate into another context, culture and language. In fact, translating is not a mirroring process; it's another example of diffraction.

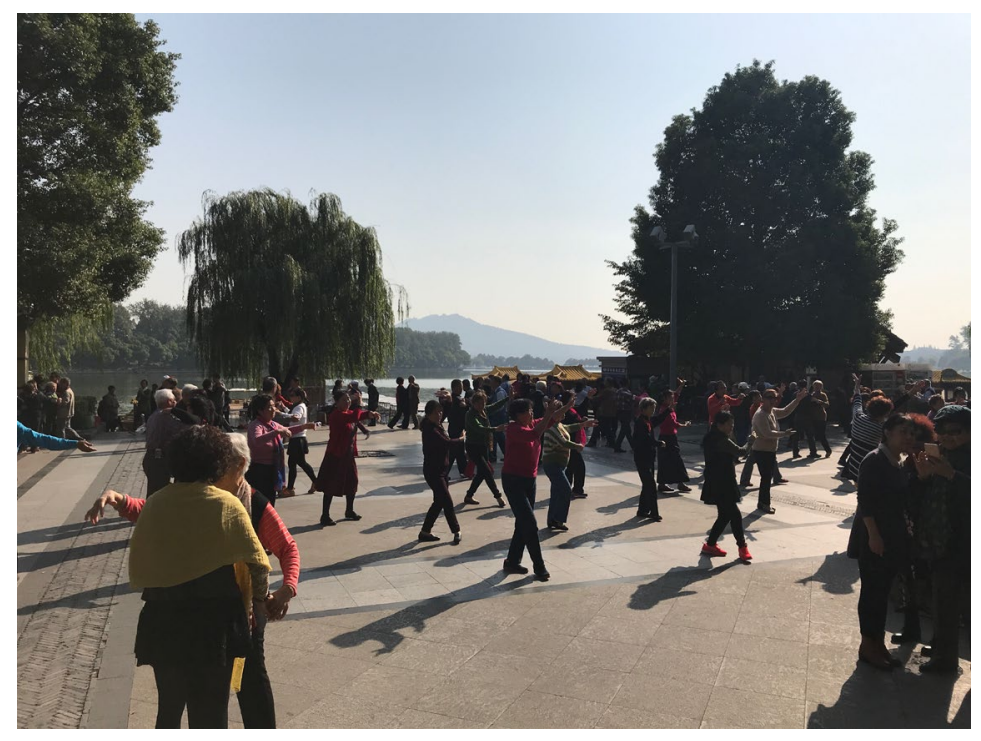

In China, a cultural context where everything was so unfamiliar to me, I often felt acutely aware of my own cultural difference. My most visible difference of having curly, blond hair was definitely noticed! Being culturally different from the majority in UK has become a familiar experience. Yet, being in China made me reflect on how my sense of belonging to England and my experience of difference are changing. The constant reminder in the news about Brexit makes me pondering about my identity/ies as shifting and evolving towards feeling more European and Italian than ever and the power of politics and its language in creating new realities and multiple identities.

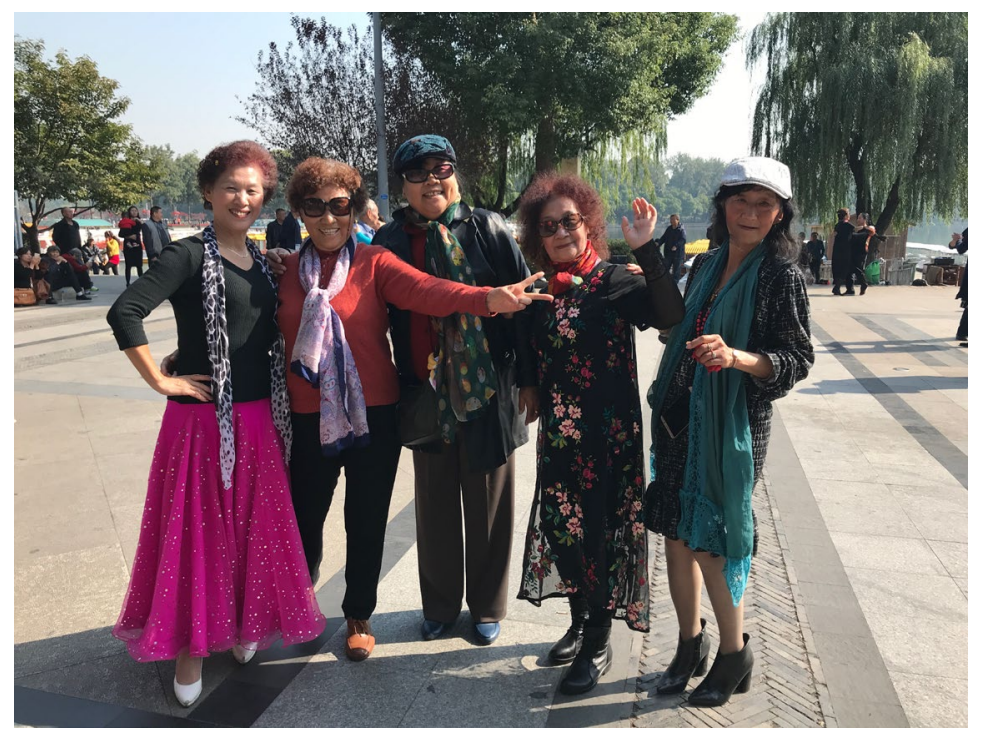

The art of hospitality: Joining the Dance

I went to visit a vast natural park on my own. I am pretty sure I was the only European person in the whole park. I heard some music and I was drawn to watch a group of Chinese people dancing. I love dancing. I quietly sat watching. People were casually watching me too.

It was fascinating to watch. There was some similarity to Italian dancing, in the sense of enjoyment and community, gentleness of movement but also difference in the way they all danced, showing their own unique style. Some were dancing in 


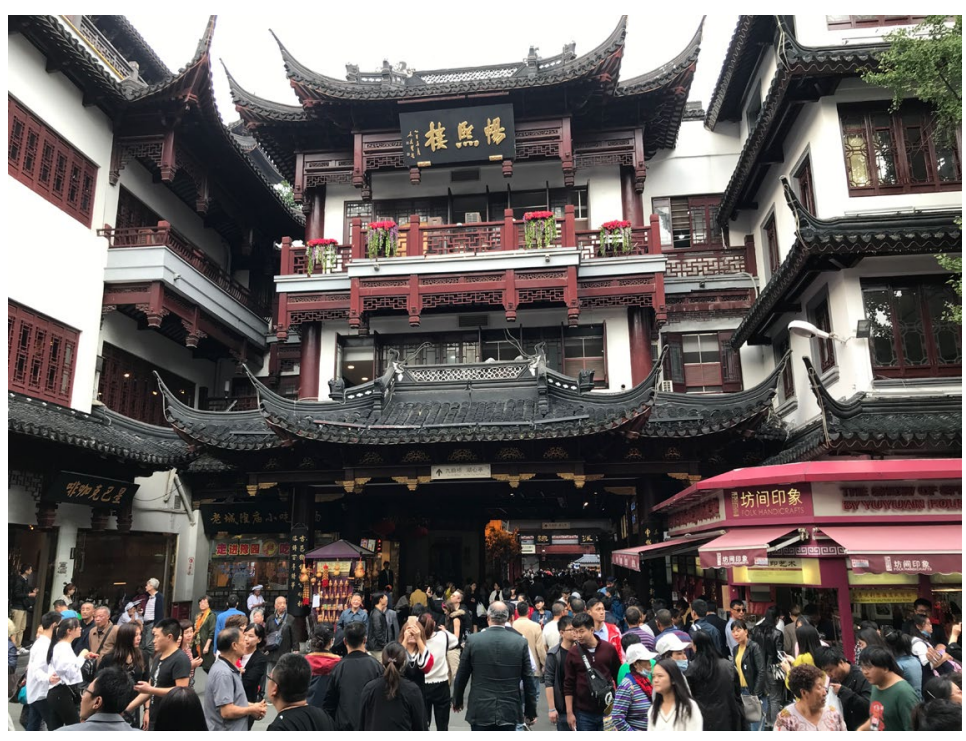

After about 10 minutes a woman approached me and offered me an orange whilst she uttered words I couldn't comprehend. I smiled, bowed and ate it. After a little while she came again towards me and talked to me. I knew she was asking me to dance. I wanted to be part of this dance. I wanted to make a connection with this unfamiliar world. I was worried about getting it right, I stumbled a few times, I kept smiling. I felt reassured that it was not important to perform the perfect dance. Dancing was a way of being with each other, being in tune with another person, trust who was leading and take pleasure in the gentleness of movement and the joy of the music. The next dance was with a man who looked like a professional dancer. All women in this small group were keen for me to accept this invitation. They offered to take a video with my phone. I was very conscious of my awkwardness looking down to study my partner's feet. Then I slowly started to relax. Nobody was really looking as if I was made to feel culturally different and performing for an audience. It was an invitation to join

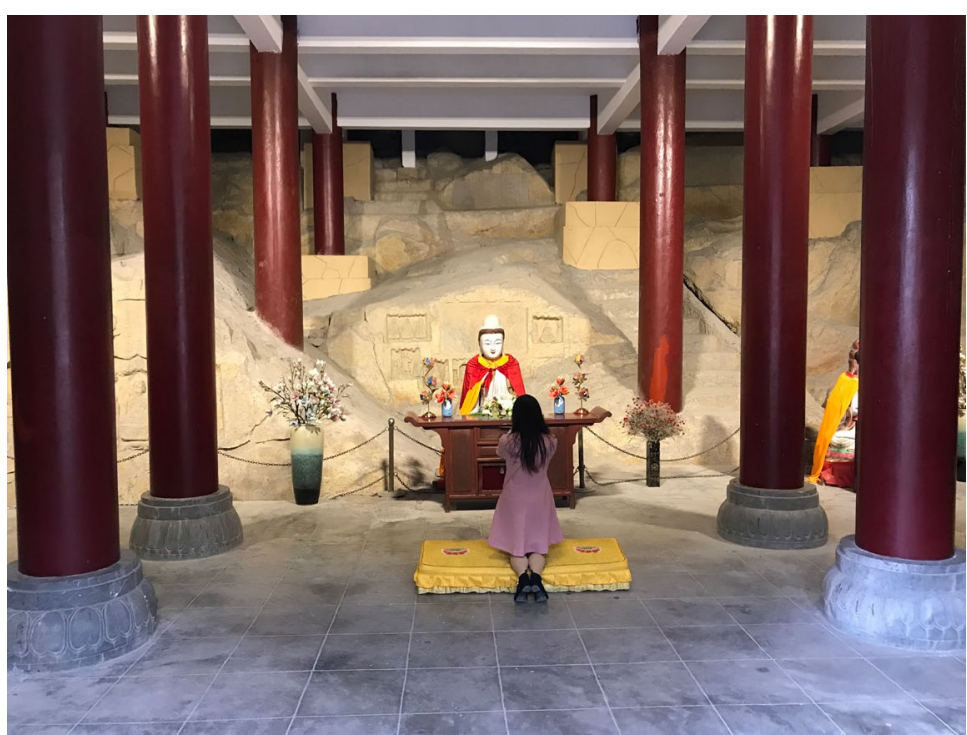

pairs, man and woman, two women, some were dancing as a group. At some point there was an elderly person being held by two people and helped to move across the floor. I started hypothesising that he was someone who had dementia or mobility problems, maybe he was a professional dancer in his life and was helped to experience movement or being reminded of his earlier life and abilities. There was great care shown in this awkward dancing. There was a strange beauty and tenderness in watching it.

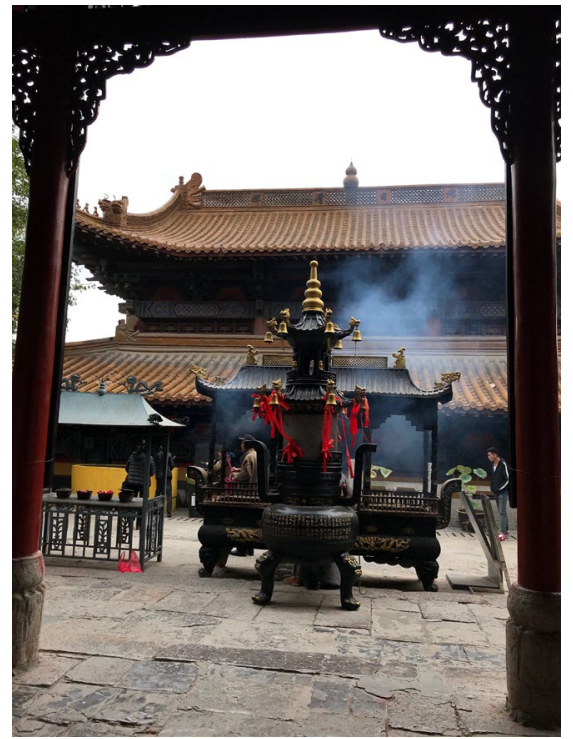
their dance.

I wanted to show my gratitude for their hospitality as I reluctantly left this magical and intimate moment of connection with some Chinese people. I asked this little group to gather and take a photo of them. There were no words we could understand but such a lot was communicated through this shared dancing experience. The art of hospitality without words: I did not feel a stranger, a foreign guest but a welcomed strange human being. 


\section{Both/And: an invitation to reverence and irreverence}

Without the local language I realised how powerless I felt and how much I had to rely on translation to understand what I was seeing within this cultural context. Nevertheless, I learned how much we communicate without words and the power of language in context.

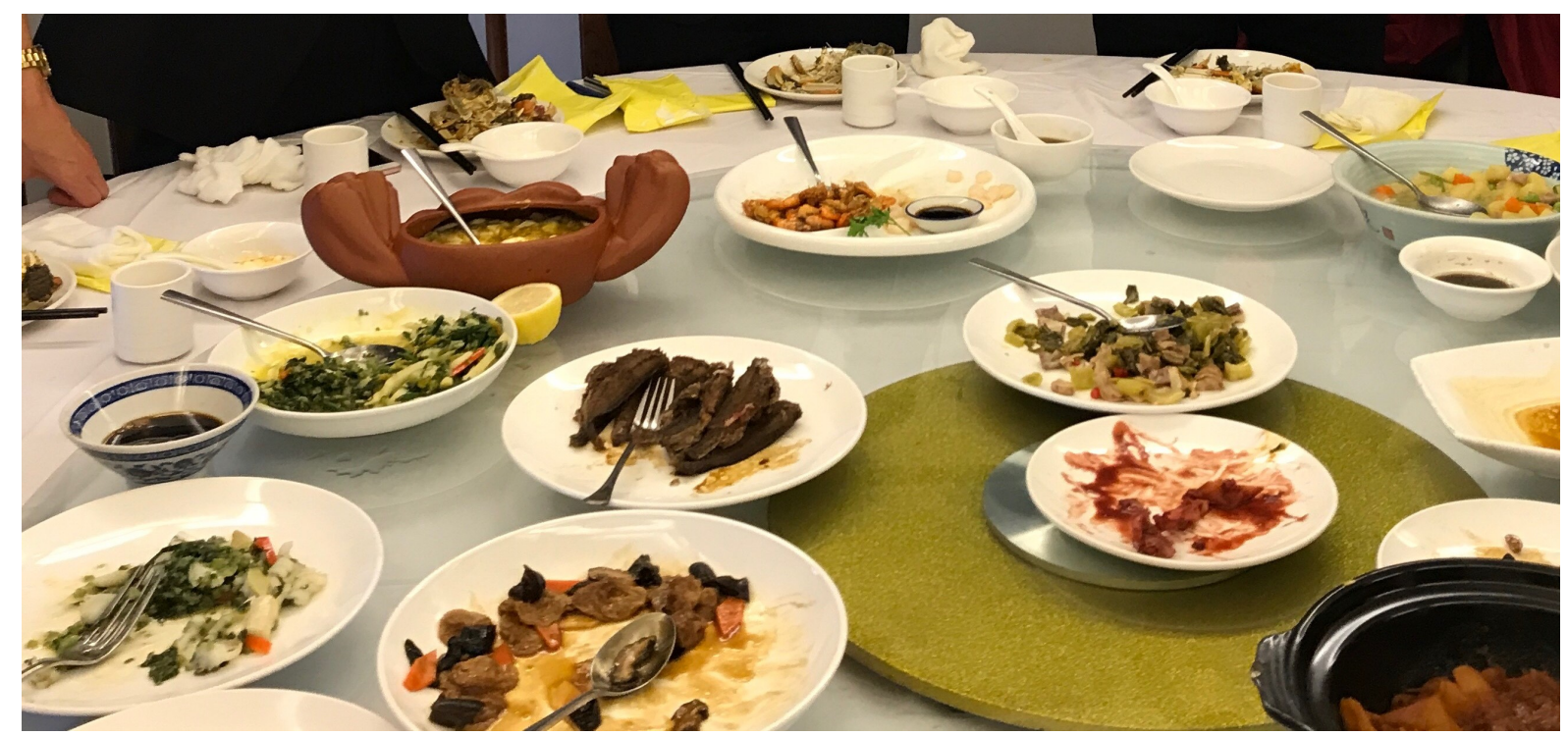

I went to a Buddhist monastery, 53 big stone steps led me inside. It felt like entering a very different world where religion, (care and beauty) was the most apparent of the Graces. I was greeted by a seemingly (from her clothing) Buddhist nun with a serious smile. There were shrines all around me in this small courtyard where many incense sticks were burning. I stood in front of a shrine and she said something with a firm voice, but I did not understand, I just knew that I was not behaving appropriately for the place. My best guess was that she was inviting me to pray. I was suddenly feeling disrespectful, as I did not know how to show my curiosity for this spiritual place. She then showed me how to bow three times so I did the same. She smiled. I felt reassured that maybe I was doing "something right". I showed her my mobile phone as a way of asking if I could take a photo. She replied with her fingers "one or two only". She offered to take a photo with my hands joined as if in prayer. She took another one, and another one and another one from a different angle. She was fully smiling now. We had made a connection without words through her irreverence to the rules of the place written on a big sign: "Do not take photographs". It was too late when I read it. I was then secretly smiling that the nun could bend the rules in the name of privileging human connection over rules! The power of influence! I am a rule breaker too and naturally irreverent! 


\section{Being an explorer in systemic practice: an invitation to dance}

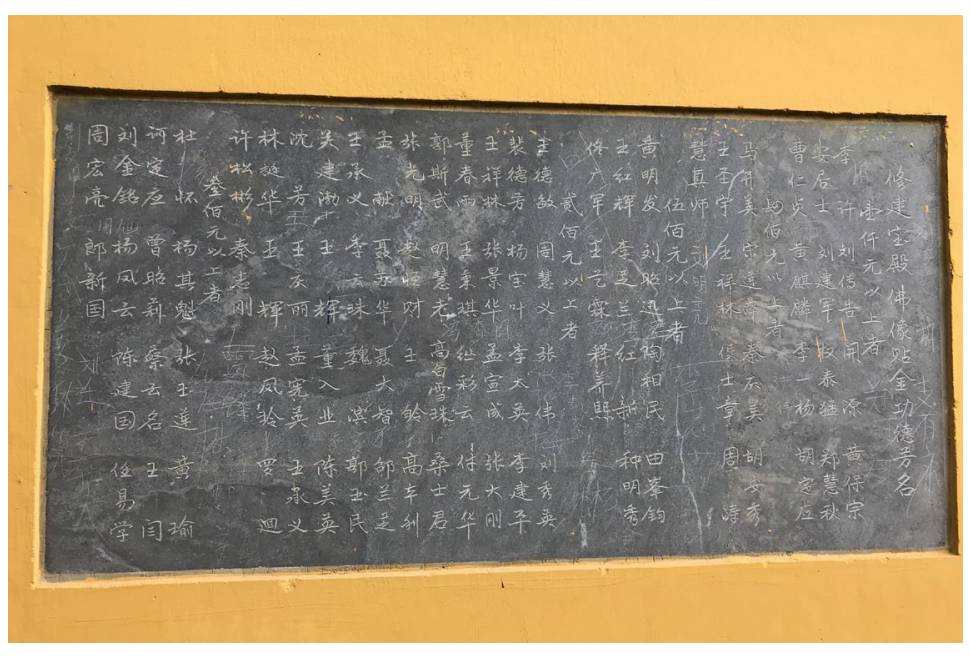

In a clinical context, when I see my clients, I have a systemic map which gives me a sense of competence and confidence in my knowledge and skills in order to hopefully be helpful. However, I need to be able to trust my clients to take me and explore their territory with fresh curiosity and becoming aware of the assumptions I make from the map!

As we receive a new referral, we start mapping out what the problem might be described and defined, some solutions or ideas about change given to us through our training, personal and professional experiences, values and assumptions. We start mapping out the context e.g. who is in the family, who is in the professional system, past and present. We have a map! However, we soon realise that this initial map is changing, as it starts showing a different kind of territory! The map becomes more like a photo taken from different stand points, all the different ideas in the family and the professional systems about defining the problem and co-creating some possible solutions or different lenses through which we can see a different territory. We need to use all our curiosity and cultural naïvete to be able to become joint explorers with the family and find ways of navigating the territory.

We might try to join the family dance as a way of respectfully exploring their territory. The art of joining is a key systemic skill which Minuchin powerfully embodied in his practice. Joining aims to be a delicate and careful process of attunement to our clients, their pace and competence in their own family dance. Minuchin was using this metaphor to convey the importance of this in establishing a therapeutic relationship. And therapy is ultimately an invitation to dance together with another. Sometimes the invitation to dance comes from the family although we are to seek permission to enter the intimacy of the dancing floor and start learning their dance to start appreciating our therapeutic posture and alliance and considering any new step. The video shows how awkward it can be! Sometimes families have stopped the family dance, they feel unable enjoy the freedom of movement and any form of playfulness or enjoyment in life and therefore the invitation to dance may come from ourselves (therapists) as we start witnessing and feeling the pain of a forgotten family dance.

However, the ethics of hospitality invites us to think about how we enter the sacred world of "the other", "the stranger" (as if we enter into a monastery) when we meet a family for the first time and how our efforts maybe be perceived. We may try to enter clients' world in a delicate and respectful way, tiptoeing. However, this is a complex process of engagement which can be perceived by clients as colonising and violence in spite of our best efforts to be a good host for our clients (Rober et al., 2010, 2017). Particularly, in a different culture or within each unique family culture our intentions and interventions maybe perceived as disrespectful and unhelpfully irreverent.

The power of language embedded in therapeutic discourses is also impacting on the way we engage and speak to our clients. The use of jargon is often taken for granted as a way to implicitly convey our sense of competence and power and carry the risk of cultural violence. Speaking the language of the other (Larner, 2015) is a useful reminder to be more aware of our position of power and the possibility 
of abusing it, hence the need to find ways of counterbalancing it with tentative offerings and room for uncovering multiple meanings.

As much as I like the Italian idea of systemic irreverence as a way to challenge the status who in working with families and organisations, we might have to be mindful of the context and sometimes privilege reverence as a way to be respectful of every culture and cultural beliefs about families, relationships and change. Here it is a final invitation to be irreverent to irreverence and embrace them both. Both/And! Respectfully irreverent and disrespectfully reverent at the same time!

\section{Cited Systemic Ideas and References}

\section{Diffraction}

Barad, Karen (2007). Meeting the universe halfway. Durham, NJ \& London: Duke University Press.

\section{The map is not the territory}

Bateson, Gregory (1972). Steps to an ecology of mind. New York, NY: Ballantine.

Hypothesising, Curiosity and Irreverence - Milan and Post Milan systemic model

Cecchin, Gianfranco (1987). Hypothesising, circularity and neutrality revisited: an invitation to curiosity. Family Process, 4, 405-413.

Cecchin, Gianfranco; Lane, Gerry \& Ray, Wendel (1992). Irreverence: a strategy for therapist's survival. London: Karnac Books.

\section{Cultural naïvete and working cross-culturally}

Dyche, Lawrence \& Zayas, Luis H. (1995). The Value of Curiosity and Naiveté for the Cross-Cultural Psychotherapist. Family Process, 34, 4, 378-389. https://doi.org/10.1111/j.1545-5300.1995.00389.x

Krause, Inga-Britt (2012). Culture and reflexivity in systemic psychotherapy. Mutual perspectives. London: Karnac Books.

Karamat Ali, Ramon (2007). Learning to be mindful of difference: teaching systemic skills in cross-cultural encounters. Journal of Family Therapy, 29, 4, 368-372. https://doi.org/10.1111/j.1467-6427.2007.00404.x

Larner, Glenn (2015). Ethical Family Therapy: speaking the language of the Other. Australian \& New Zealand Journal of Family Therapy, 36, 434-449.

Mason, Barry \& Sawyer, Alice (Eds.) (2002). Exploring the unsaid: Creativity, risks, and dilemmas in working cross-culturally. London: Karnac Books.

Nolte, Lizette (2007). White is a colour too: engaging actively with the risks, challenges and rewards of crosscultural family therapy training and practice. Journal of Family Therapy, 29, 4, 378-388.

https://doi.org/10.1111/j.1467-6427.2007.00406.x

\section{The Social Graces, intersectionality and self-reflexivity}

Burnham, John (2011). Developments in social GRRRAAACCEEESSS: visible-invisible and voiced-unvoiced. In Krause, Inga-Britt (Ed.) Culture and reflexivity in systemic psychotherapy: Mutual perspectives. London: Karnac Books.

Burnham, John (1993). Systemic supervision: the evolution of reflexivity in the context of the supervisory relationship. Human Systems: The Journal of Systemic Consultation and Management, 4, 349-381. 
Butler, Catherine (2009). Sexual and gender minority therapy and systemic practice, Journal of Family Therapy, 31, 4, 338-358. https://doi.org/10.1111/j.1467-6427.2009.00472.x

Divac, Alexandra, \& Heaphy, Grace (2005). Space for GRRAACCES: training for cultural competence in supervision. Journal of Family Therapy, 27, 3, 280-284. https://doi.org/10.1111/j.1467-6427.2005.00318.x

Roper-Hall, Alison (1998). Working systemically with older people and their families who have 'come to grief'. In P. Sutcliffe, G. Tufnell and U. Cornish (Eds.) Working with the Dying and Bereaved: Systemic Approaches to Therapeutic Work (pp. 177-207). London: Macmillan.

Roper-Hall, Alison (2008). Systemic interventions and older people. In R. Woods and L. Clare (Eds.), Handbook of the Clinical Psychology of Ageing (2nd ed.). London: Wiley.

Sermijn, Jasmina; Devlieger, Patrick \& Loots, Gerrit (2008). The narrative construction of the self: Selfhood as a rhizomatic story. Qualitative Inquiry, 20, 10, 1-19. https://doi.org/10.1177/1077800408314356

Smith, Julie (2016). Sailing through social LA GRRAACCEESS: tool for deconstructing and facilitating reflective and reflexive practice. Reflective Practice, 17, 5570-582. https://doi.org/10.1080/14623943.2016.1184634

Totsuka, Yoko (2014). 'Which aspects of social GGRRAAACCESSS grab you the most?' The social GGRRAAACCEESSS exercise for a supervision group to promote therapists' self- reflexivity. Journal of Family Therapy, 36, S1, 86-106. https://doi.org/10.1111/1467-6427.12026

\section{Joining and the Family Dance - the structural model}

Minuchin, Salvador and Fishman, Charles, H. (1981). Family therapy techniques. Cambridge, MA: Harvard University Press.

\section{The ethics of hospitality}

Aman, Jodi (2006). Therapist as host: making guests feel welcome. The International Journal of Narrative Therapy and Community Work, 2006, No.3. www.dulwichcentre.com.au

Bazzano, Manu (2015). Therapy as unconditional hospitality. Psychotherapy and Politics International. 13, 1, 413 (2015). Published online 6 February 2015 in Wiley Online Library. https://doi.org/10.1002/ppi.134

Rober, Peter \& Seltzer, Michael (2010). Avoiding a coloniser positions in the therapy room: some ideas about the challenges of dealing with the dialectic of misery and resources in families. Family Process, 49, 1, $123-137$ https://doi.org/10.1111/j.1545-5300.2010.01312.x.

Rober, Peter and De Haene, Lucia (2017). Hospitality in Family Therapy practice: a further engagement with Jacques Derrida. Australian and New Zealand Journal of Family Therapy, 38, 378-390.

\section{Both/And - Socio-constructionism - multiple lenses and perspectives}

Burr, Vivienne (1995). Social constructionism. New York, NY: Routledge. 


\section{Reflecting on Chiara's reflection}

\section{Charlotte Chiu}

I am Charlotte, born Chinese in Hong Kong, who came to the UK in my 20s during the 1980s for a postgraduate study. I never made it back and became what some call a "first-generation immigrant". I have made the UK my home as a member of the "third group": too Chinese to be English; too English to be Chinese; a distinct group that is good at adapting to both cultures but doesn't feel it belongs to either. Hong Kong, my country of origin is an ex-colonial territory of the UK, which returned to China's rule in 1997. It used to, and continues to, serve as a bridge between the West and Mainland China, remaining one of many "Special Economic Zones" of China.

Through a colleague I responded to Chiara's request to contribute my reflections to her writing about her visit to China. I asked why she wanted comment from a Chinese therapist, and she said she wanted a different perspective. I wondered: "Does that mean she wants a near-race or culture comment?" I decided to respond to her invitation using the lens of race, ethnicity and culture from my position as a Chinese immigrant to the UK, from what I know of what Chinese means to me.

I have always felt proud to be invited as "Chinese". This kick started the process of writing and talking to Chiara, a stranger other than we are both family therapists. In turn she sent me her writing and video about China. It was really interesting to hear her reflections as a female European tourist in China, a land where I have never lived but to which I feel mysteriously connected through my racial link.

I was struck by the video which showed Chiara's dance in the park with a Chinese male partner. His posture is serious, professional, straight backed, with meticulously positioned hands and arms, and coordinated foot work, leading Chiara who seemed to thoroughly enjoy the experience. I noticed he looked into the air, away from Chiara, deliberately avoiding eye contact. I have no doubt that this was intentional. They both seemed to concentrate on the moves, connecting through the movements, but not necessarily in tune with each other. This is in contrast to what I saw on the BBC Programme "Strictly Come Dancing". The professional dancers and mentors work on their relationship with their dancing partners, helping them to loosen up, trusting each other, building techniques and giving soul to the dance.

This led me to think about cultural differences in teaching and learning choreography. How are dancing, exercising in the park and welcome to tourists shown in different countries or cultures? How are values and beliefs that are embedded in their history shown at this particular time? How might social, economic and political contexts influence dancing, exercising in the park or welcoming tourists? I wonder what Chinese people expect in response to "dancing, exercising in the park and welcoming tourists" now or fifty years ago or fifty years ahead.

I remember the 2008 Beijing Olympic Games opening ceremony which show-cased a drum dance involving thousands of people all moving uniformly and in time with each other. Then, in 2012, the London Olympic Games opening ceremony was a lively musical show with dancers in many different scenes. It attracted the audience through many differences going on at the same time, creating an electric and ecstatic feel. I feel the dance metaphor brings forth the richness of two cultures, different in style but similarly enjoyable.

I like Chiara's reflections on her visit to China and how they connect with her systemic practice. Her reflection invites me to become curious about her cultural identity and what it means being an Italian 
living in UK. Wallisa and Singh (2014) looked at "construct whiteness", how these constructions or discourses facilitate or constrain talk about whiteness and how this influences what therapists do in therapy. I wonder how Chiara's "whiteness" might influence her curiosity in meeting other cultures? She mentioned physical difference, language difference and I wonder about her position of power as a white woman. I wonder how her tourist experience might change if she were to live in China for a length of time. In clinical practice I wonder if clinicians are like tourists in the eyes of families, who will then try to impress us and show us what they think we want to see? Or we are positioned as a tourist by ourselves or even by the institutional system?

As for myself, I think my experience of being an immigrant to the UK carries shadows of historical colonialism, racism and racial hierarchical discourses. My decision to stay after my studies was based on achieving a life different to that which I had experienced in Hong Kong. Krause (2014) suggests that to understand the complex nature of culture one needs to consider the interplay between social contexts and inner emotional psychological dispositions. She refers to conscious and unconscious outlooks and attitudes which provide those who embody culture with meaning and the meaning in turn to shape the individual and culture. I think we need to be aware, not only of the issue of categorisation - difference or similarity - within social contexts, but also of thinking and reflecting as a continuous process.

I wonder about Chiara's relationship with dance before and after her move from Italy to the UK. I believe I am more at ease in the UK because of the embodied experience that it is okay to appear clumsy. I am more self-conscious in Hong Kong where my embodied experience of criticism and judgement would emerge when I don't get it right. This made me wonder about the embodied experience of families' values, beliefs, actions and behaviours in therapy. How do we understand and think with them about the effect of being in a family therapy room with professionals who are not part of their community, culture or systems?

It is also interesting to hear Chiara's feelings, experience and connections with the Chinese culture. Maybe mutual acceptance created a positive experience for all. However, I wonder about the parallel experience of some migrant families in the UK, especially if they look different or may not speak English. I wonder if warmth, humility and acceptance can help connect with people from a foreign land. I wonder about the stories families might tell about arriving in the "foreign land" in a family therapy environment. It is important for therapists to look at their relationship with their own culture, tuning into their own cultural identity and turning to cultural reflexivity to know how to position themselves towards others. Rober \& De Haene (2014) further suggest family therapists need to examine their own humanity and mortality, not just focusing on similarity and difference in culture. In my view, connecting through humanity should be extended into the wider social world of the clinical team, the services, the communities and the society. It would then naturally follow that "humanity" would be in the therapy room.

\section{References}

Krause, Inga-Britt (2014). The complexity of cultural competence. In Lowe, F. (Ed.) Thinking Space: Promoting Thinking About Race, Culture and Diversity in Psychotherapy and Beyond. London: Karnac. pp.109-126.

Rober, Peter \& De Haene, Lucia (2014). Intercultural therapy and the limitations of a cultural competency framework: about cultural differences, universalities and the unresolvable tensions between them. Journal of Family Therapy, 36, S.1, 3-20. https://doi.org/10.1111/1467-6427.12009

Wallisa, Jennifer \& Singh, Reenee (2014). Constructions and enactments of whiteness: a discursive analysis. Journal of Family Therapy, 36, S.1, 39-64. https://doi.org/10.1111/j.1467-6427.2012.00602.x 


\section{Imagining Chiara in China}

\section{Freda McEwen}

Though in China, I felt at home

The world though big is small

The geographical distance does not segregate us

from wanting to explore and get acquainted

Though the initial reaction of uncertainty and curiosity

Brought goose bumps

Overcome by a chill I cannot comprehend

Not sure how I will be accepted

Because of my appearance and cultural difference

Sitting down formulating and mapping out

Thoughts, concerns and how to break the silence

Being in a strange place and taking baby steps

Being careful not to fall and embarrass myself

Confused as to what action to take

To join or not to join

Wondering when to jump in

Trying at the same time not be too overbearing

Or perhaps too comfortable

Else I forget my purpose

Drawing on the detachment and discomfort

brought about by a face with no expression

Unsure of what to expect from him

Careful not to step on his toes

The tranquillity and chill of a spiritual being

Unsure what to make out of it

The richness of the culture

The wealth that is displayed everywhere I go 
I was astonished

Especially coming from

a perceived superior country

The $1^{\text {st }}$ world country

Which formed my opinion

But I found this place exotic and mind-blowing

I was equipped with power from onset like an authority

in deciding the next step

But I fluttered

I had to accept the fact that this is new

And I need to learn

Removing the focus from myself as a tourist

Removing the baggage of prejudices and stereotype

Which I carried on my shoulders

It is not just about me and my personal circumstances

But others who happen to have strong emotional connection to the place

Which they called home

People who have formed an attachment from onset

A place of refuge

Venturing into men's world was intriguing

But normal where I come from

I am a face they can never forget

Different from what they are used to

My age was unnoticeable

I was just one of them

And am glad I took this trip

A trip that enabled me to understand myself a lot better. 


\section{Authors}

Chiara Santin is a systemic and family psychotherapist, supervisor and trainer. She is also Director of Rainbow Family Therapy Services, Brighton, UK.

Email: rainbow.Itd@btinternet.com

URL: http://www.familytherapyservicesrainbow.org

\section{Citation}

Santin, Chiara; Chiu, Charlotte \& McEwan, Freda (2019). Being Systemic as a Way of Life. Reflections on a Trip to China. Murmurations: Journal of Transformative Systemic Practice, 2, 1, 67-80

https://doi.org/10.28963/2.1.9 